AUTHORS:

Zander R. Human ${ }^{1}$

Bernard Slippers ${ }^{2}$

Z. Wilhelm de Beer ${ }^{1}$

Michael J. Wingfield ${ }^{1}$ iD

Stephanus N. Venter ${ }^{1}$ (DD

\section{AFFILIATIONS:}

'Department of Microbiology and Plant Pathology, Forestry and Agriculture Biotechnology Institute, University of Pretoria, Pretoria, South Africa

2Department of Genetics,

Forestry and Agriculture

Biotechnology Institute,

University of Pretoria, Pretoria,

South Africa

\section{CORRESPONDENCE TO:}

Wilhelm de Beer

\section{EMAIL:}

Wilhelm.debeer@fabi.up.ac.za

\section{DATES:}

Received: 18 July 2016

Revised: 29 Aug. 2016

Accepted: 31 Aug. 2016

\section{KEYWORDS:}

Streptomyces; Ophiostomatales;

Pinus; mutualism; antibiotics

\section{HOW TO CITE:}

Human ZR, Slippers B, De Beer ZW, Wingfield MJ, Venter SN. Antifungal actinomycetes associated with the pine bark beetle, Orthotomicus erosus, in South Africa. S Afr J Sci. 2017;113(1/2), Art. \#2016-0215, 7 pages. http://dx.doi.org/10.17159/ sajs.2017/20160215

\section{ARTICLE INCLUDES: \\ $\times$ Supplementary material \\ $\times$ Data set}

\section{FUNDING:}

DST-NRF Centre of Excellence in Tree Health Biotechnology; National Research Foundation (South Africa); University of Pretoria

\title{
Antifungal actinomycetes associated with the pine bark beetle, Orthotomicus erosus, in South Africa
}

\begin{abstract}
Actinomycete bacteria are often associated with insects that have a mutualistic association with fungi. These bacteria are believed to be important to this insect-fungus association as they produce antibiotics that exclude other saprophytic fungi from the immediate environment. The aim of this study was to investigate the presence of potentially protective actinomycetes associated with Orthotomicus erosus, an alien invasive pine bark beetle, in South Africa. This bark beetle and its relatives have an association with Ophiostomatales species which are often the only fungi found in the bark beetle galleries. We hypothesised that antibiotic-producing actinomycetes could be responsible for the paucity of other fungi in the galleries by producing compounds to which the Ophiostoma spp. are tolerant. Several actinomycetes in the genus Streptomyces and one Gordonia sp. were isolated from the beetle. Interestingly, most isolates were from the same species as actinomycetes associated with other pine-infesting insects from other parts of the world, including bark beetles and the woodwasp Sirex noctilio. Most actinomycetes isolated had strong antifungal properties against the selected test fungi, including Ophiostoma ips, which is the most common fungal symbiont of Orthotomicus erosus. Although the actinomycetes did not benefit Ophiostoma ips and the hypothesis was not supported, their sporadic association with Orthotomicus erosus suggests that they could have some impact on the composition of the fungal communities present in the bark beetle galleries, which is at present poorly understood.

\section{Significance:}

- Discovery of four putative undescribed Streptomyces spp. with antibiotic potential

- First record of the introduction of actinomycete bacteria with pine-infesting insects into South Africa

- Actinomycetes from South Africa group with undescribed Streptomyces spp. from pine-infesting insects of North America
\end{abstract}

\section{Introduction}

The European bark beetle Orthotomicus erosus (Curculionidae: Scolytinae) is an introduced pine-infesting pest in South Africa. ${ }^{1}$ It typically infests stressed or dying trees and introduces blue stain fungi that invade the sapwood and depreciate the timber value. ${ }^{1,2}$ The blue stain fungus Ophiostoma ips (Ascomycota: Ophiostomatales) is the dominant associate of 0 . erosus in South Africa, but several other related fungi co-occur with this species in the beetle galleries. ${ }^{3}$ Although 0 . ips consistently co-occurs with 0 . erosus at varying frequencies ${ }^{3,4}$, it is not a serious pathogen to living pine trees ${ }^{5}$ and its role as symbiont remains uncertain, as is the case with most ophiostomatoid fungi associated with conifer-infesting bark beetles ${ }^{6}$. Although the fresh bark beetle galleries represent an environment rich in nutrients and other growth substrates, it is remarkable that this niche is seldom overgrown with common mould fungi.

The presence of primarily Ophiostoma spp. and their relatives and the lack of contaminating moulds in the galleries of the beetles has raised the question as to the factors that increase the fitness of fungi commonly associated with the insect, over other fungi expected to be found in these environments. One possibility is that antibiotic-producing actinomycetes could play a role in this symbiotic relationship. In this regard, actinomycetes are the most important producers of antibiotics ${ }^{7}$ with more than 100000 antibiotic compounds estimated to be produced by members of the genus Streptomyces ${ }^{8}$. The formation of heat and desiccation-resistant spores is also a common feature of these bacteria ${ }^{7}$ and the hydrophobicity of their spores can facilitate their transport ${ }^{9}$. All these features could be important in their association with arthropods such as insects and mites. ${ }^{10}$

There are various symbiotic communities in which insects exploit actinomycetes to produce metabolites for protection..$^{10-13}$ Examples include attine ants (Attini: Formicidae) that have co-evolved with actinomycetes in the genus Pseudonocardia to protect their food source against a parasite. ${ }^{11}$ The ants cultivate a basidiomycete fungus that is used for nutrition, ${ }^{11}$ but the fungal garden can be parasitised by another fungus (Escovopsis spp.), thus threatening the survival of the entire colony. Secondary metabolites produced by the actinomycetes residing on the ants' integuments protect the crop by inhibiting the growth of Escovopsis. ${ }^{11,12}$ Actinomycete-insect symbioses also occur with the southern pine beetle, Dendroctonus frontalis (Curculionidae: Scolytinae), in its native environment in the USA. ${ }^{13}$ Survival of larvae in the galleries of these beetles is negatively impacted by Ophiostoma minus, a fungal symbiont of mites that competes with the fungal mutualist, an Entomocorticium sp., of the beetle. Streptomyces symbionts in the mycangium of $D$. frontalis produce antibiotics that inhibit the growth of 0 . minus, whereas the mutualistic fungus is tolerant to the antibiotics. ${ }^{13}$

The aim of this study was to isolate and identify putative actinomycete symbionts from the invasive 0 . erosus in South Africa, and to determine whether they have antifungal properties that might be important in this niche. We hypothesised that actinomycete symbionts of 0 . erosus produce antifungal compounds, similar to cycloheximide that is known to have broad antifungal effects except on Ophiostoma spp. and their relatives. ${ }^{14,15}$ We expect that these compounds will negatively affect the fitness of potentially competing saprophytic fungi from the galleries. 


\section{Materials and methods}

\section{Bacterial isolation}

Orthotomicus erosus galleries were collected from dead Pinus patula trees in the Lothair plantation, Mpumalanga Province, South Africa. In total, 40 beetles were removed from these galleries and individually crushed in sterilised $10 \%$ phosphate-buffered saline solution (PBS). Three tenfold serial dilutions were prepared for each sample using $10 \%$ PBS.

An aliquot of $100 \mu \mathrm{L}$ of each dilution was inoculated onto chitin agar ${ }^{16}$ in duplicate, supplemented with antibiotics (cycloheximide $5 \mathrm{mg} / \mathrm{L}$ and nystatin 10000 units/L). ${ }^{12}$ These plates were incubated for approximately 30 days at $28{ }^{\circ} \mathrm{C}$ during which they were inspected daily for growth. Isolates presumed to be actinomycetes based on their morphology were selected and inoculated onto yeast malt extract glucose agar (YMEA) - consisting of $1 \%$ malt extract (Biolab Diagnostics, Johannesburg, South Africa), 0.4\% yeast extract (0xoid, Hampshire, England), 0.4\% D-glucose (Merck Chemicals, Johannesburg, South Africa) and $0.12 \%$ bacteriological agar (Biolab Diagnostics) $)^{12}-$ and incubated at $28^{\circ} \mathrm{C}$ until sufficient growth had occurred.

\section{DNA sequencing}

Fifteen isolates were collected and DNA was extracted using a Quick-

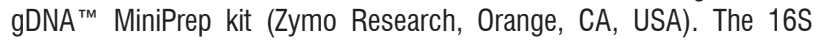
rRNA gene was amplified and partially sequenced using the primers pA and $\mathrm{pH}$ previously designed by Edwards et al. ${ }^{17}$ Subsequently, the trp $B$ (tryptophan synthase $\beta$-subunit), rpoB (RNA polymerase $\beta$-subunit) and gyrB (DNA gyrase $\beta$-subunit) genes were amplified for eight of the strains grouping with other pine associated Streptomyces isolates. Amplification of the $\operatorname{trp} B$ and $r p o B$ genes followed the methods of Guo et al. ${ }^{18}$ and that for the gyrB gene followed the method of Rong et al. ${ }^{19}$ All reactions were performed on a Veriti ${ }^{\mathrm{T} M}$ Thermal Cycler (Applied Biosystems, Foster City, CA, USA) using Super-Therm Taq polymerase (Southern Cross Biotechnology, Cape Town, South Africa). Polymerase chain reaction (PCR) products were verified using agarose gel electrophoresis and purified using $E$. coli exonuclease I and alkaline phosphatase.

Sequencing of the PCR products for 16S rRNA, gyrB, rpoB, trpB was performed using the ABI BigDye Terminator v3.1 (Applied Biosystems) following the protocols previously described. ${ }^{17-19}$ Precipitation of sequencing reactions was done through sodium acetate precipitation and the sequencing products were analysed on an $\mathrm{ABI} 3130$ sequence analyser (Applied Biosystems).

A BLASTN ${ }^{20}$ search was performed to identify the closest matching sequences in GenBank ${ }^{21}$. A search was also performed against the Ribosomal Database Project (RDP) 22 using the Seqmatch platform. Similar sequences were downloaded for phylogenetic analyses. Sequences representing the closely related type strains were also obtained.

\section{Phylogenetic analyses}

To determine the relationship between sequences obtained and the published reference sequences, a phylogenetic tree based on the $16 \mathrm{~S}$ rRNA sequence alignment was constructed employing a maximum likelihood analysis. The alignment was made using the online version of MAFFT version $6 .{ }^{23}$ In addition, a concatenated alignment consisting of the $g y r B, r p o B$ and $\operatorname{trp} B$ genes of a selected number of isolates were made using SequenceMatrix. ${ }^{24}$ The appropriate nucleotide substitution model was selected for both sets of genes using JModeltest version 2.1.1. ${ }^{25,26}$ Phylogenetic tree construction was performed using the maximum likelihood approach in PhyML version 3.0. ${ }^{25}$ The models used were $\mathrm{TIM} 3+\mathrm{I}+\mathrm{G}\left(16 \mathrm{~S}\right.$ rRNA) and $\mathrm{GTR}+\mathrm{I}+\mathrm{G}(\mathrm{gyr} B$, $\operatorname{trp} B$ and $r p o B) .{ }^{25,26}$ Trees were visualised using Mega 5.05. ${ }^{27}$

\section{Dual-plate bioassay challenges}

A preliminary assay was performed for all 15 actinomycete isolates to serve as a selection step for further antifungal assays. Four different isolates were inoculated onto the four quadrants of YMEA plates and these were incubated for 2 weeks. These test plates were then inoculated with a Trichoderma sp. by placing a plug, $15 \mathrm{~mm}$ in diameter, at the centre of the pre-inoculated plate. Any isolates showing antifungal activity were subjected to further in-vitro assays.

Bioassay challenges were done for the selected isolates following the approach of Cafaro and Currie ${ }^{12}$. Streptomyces isolates were inoculated (10 mm in diameter) onto a 90-mm Petri dish containing YMEA. ${ }^{12}$ These plates were incubated for 21 days. Three fungal species were chosen for use in bioassays. These three species were the most common fungal associate of 0 . erosus ( 0 . ips), a common saprophyte (Trichoderma sp.) and a commonly occurring pine endophyte (Diplodia sapinea). D. sapinea and Trichoderma spp. are regularly isolated from pine wood and are potential competitors of 0 . ips (Table 1). Isolates were obtained from the Culture Collection of the Forestry and Agricultural Biotechnology Institute (FABI) of the University of Pretoria. A single $15-\mathrm{mm}$ fungal plug was inoculated at the edge of the 21-day-old plates and incubated at $25^{\circ} \mathrm{C}$ until sufficient growth on control plates was observed. Two repeats were performed for each pairing. Plates were examined and the average zone of inhibition measured for all the bioassay challenges.

Table 1: Results of bioassays in which actinomycete isolates were tested for their ability to inhibit growth of Trichoderma sp. (a saprophyte), Diplodia sapinea (an endophyte) and Ophiostoma ips (a fungal symbiont)

\begin{tabular}{l|c|c|c}
\hline \hline \multirow{2}{*}{$\begin{array}{c}\text { Actinomycete } \\
\text { isolate }\end{array}$} & \multicolumn{3}{|c}{ Fungal isolate } \\
\cline { 2 - 4 } & Trichoderma sp. & Diplodia sapinea & Ophiostoma ips \\
\hline BCC1197 & +++ & +++ & +++ \\
\hline BCC1193 & ++ & ++ & +++ \\
\hline BCC1195 & ++ & ++ & +++ \\
\hline BCC1194 & ++ & ++ & +++ \\
\hline BCC1189 & ++ & ++ & +++ \\
\hline BCC1191 & ++ & ++ & +++ \\
\hline BCC1188 & ++ & ++ & +++ \\
\hline BCC1190 & ++ & ++ & +++ \\
\hline BCC1204 & + & ++ & +++ \\
\hline BCC1196 & ++ & + & ++ \\
\hline BCC1198 & + & + & ++ \\
\hline
\end{tabular}

Inhibition zones: +++, $15 \mathrm{~mm} ;++, 10 \mathrm{~mm} ;+, 5 \mathrm{~mm}$

Following the above-mentioned challenges, the beetle symbiont fungus 0 . ips, and one of the bacteria (isolate BCC1988), were simultaneously inoculated on YMEA plates. Isolate BCC1988, representative of the most commonly recurring phylogenetic group associated with the beetle, was inoculated at the centre of $90-\mathrm{mm}$ Petri dishes and a single $15-\mathrm{mm}$ 0 . ips plug was inoculated at the edge of the same plate. This plate was incubated at $25{ }^{\circ} \mathrm{C}$ until sufficient growth had been observed and the result was recorded. This trial was repeated.

\section{Results}

\section{Isolates and DNA sequence based identifications}

Fifteen actinomycete isolates were obtained from the 400 . erosus individuals collected in this study (Table 2; Figure 1). These isolates were obtained from 11 different beetles, with one isolate representative of each actinomycete taxon selected from each beetle. Partial 16S rRNA sequences were obtained for all 15 isolates. Isolates were all initially identified based on the best matches for the 16S rRNA gene sequences in GenBank and the RDP database. Based on these data, all but one isolate (a species of Gordonia) belonged to the genus Streptomyces. 
Isolates were deposited in the Bacterial Culture Collection (BCC) of FABI, and 16S rRNA (Table 2) and protein-coding gene sequences (Table 2) were deposited in NCBI GenBank.

\section{Phylogenetic analysis}

\section{S rRNA}

According to RDP Seqmatch, 8 of the 14 isolates initially identified as Streptomyces spp. had sequences most similar to the sequence of the type strain of $S$. ambofaciens. In the $16 S$ rRNA based phylogenetic analysis, these isolates grouped in a single clade together with isolates from other pine-infesting insects. This clade had $94 \%$ bootstrap support (Figure 1). Another isolate from the southern pine beetle ${ }^{13,28}$ associated with this group, but the grouping was not well supported. None of the type strains' sequences formed part of this clade.

Two of the remaining isolates clustered closely with $S$. sanglieri and $S$. atratus in a well-supported group (99\%). A further two isolates were related to the latter isolates but were clearly separated from the initial clade and formed a separate clade. Of the remaining isolates, BCC1197 grouped most closely with the type strain sequence (Streptomyces alni), but was well separated and there was no clear bootstrap support for their association.

Table 2: $\quad$ Streptomyces isolates for which sequences were produced in this study (GenBank accession numbers in bold type) and reference sequences generated in previous studies (GenBank accession numbers in normal type)

\begin{tabular}{|c|c|c|c|c|c|}
\hline & & & \multicolumn{3}{|c|}{ Gene region } \\
\hline Species & Isolate numbers* & 16S rRNA & $\operatorname{trpB}$ & гроB & gyrB \\
\hline Streptomyces phaeoluteichromatogenes ${ }^{\top}$ & NRRL B-5799 & AJ391814 & HG423654 & HG423678 & HG423666 \\
\hline S. misionensis ${ }^{\top}$ & CBS 885.69 & EF178678 & HG423655 & HG423679 & HG423667 \\
\hline S. ambofaciens ${ }^{\top}$ & NRRL ISP-5053 & AB184182 & HG423656 & HG423681 & HG423668 \\
\hline S. lienomycini ${ }^{\top}$ & NRRL B-16371 & AJ781353 & HG423657 & HG423683 & HG423669 \\
\hline S. rubrogriseus ${ }^{\top}$ & NRRL B-16375 & AB184681 & HG423658 & HG423684 & HG423672 \\
\hline S. collinus ${ }^{\top}$ & NRRL B-5412 & AB184123 & HG423659 & HG423680 & HG423671 \\
\hline S. levis ${ }^{\top}$ & NRRL B-16370 & AB184670 & HG423660 & HG423682 & HG423670 \\
\hline S. janthinus ${ }^{\top}$ & CBS 909.68 & AB184851 & HG423661 & HG423685 & HG423673 \\
\hline S. albidoflavus ${ }^{\top}$ & CBS 416.34 & AB184255 & FJ406450 & FJ406439 & FJ406417 \\
\hline S. cinereorectus ${ }^{1}$ & NRRL B-16360 & AB184646 & EF661795 & EF661774 & EF661732 \\
\hline Streptomyces sp. SA3ActG & SA3ActG ${ }^{29}$ & HM235477 & NZ_ADXA01000162 & NZ_ADXA01000004 & NZ_ADXA01000012 \\
\hline Streptomyces sp. SPB078 13,28 & SPB078 10,25 & EU798708 & NZ_GG657742 & NZ_GG657742 & NZ_GG657742 \\
\hline Streptomyces sp. SPB074 & SPB07428 & EU798707 & NZ_GG770539 & NZ_GG770539 & NZ_GG770539 \\
\hline Streptomyces sp. & BCC1191 & HG423693 & HG423662 & HG423689 & HG423675 \\
\hline Streptomyces sp. & BCC1192 & HG423694 & HG423663 & HG423688 & HG423677 \\
\hline Streptomyces sp. & BCC1195 & HG423697 & HG423664 & HG423686 & HG423676 \\
\hline Streptomyces sp. & BCC1188 & HG423690 & HG423665 & HG423687 & HG423674 \\
\hline Streptomyces sp. & BCC1194 & HG423696 & KM031100 & KM031094 & KM031096 \\
\hline Streptomyces sp. & BCC1189 & HG423691 & KM031103 & KM031095 & KM031099 \\
\hline Streptomyces sp. & BCC1193 & HG423695 & KM031101 & KM031093 & KM031098 \\
\hline Streptomyces sp. & BCC1190 & HG423692 & KM031102 & KM031092 & KM031097 \\
\hline Streptomyces sp. & BCC1196 & HG423703 & & & \\
\hline Streptomyces sp. & BCC1197 & HG423702 & & & \\
\hline Streptomyces sp. & BCC1198 & HG403701 & & & \\
\hline Streptomyces sp. & BCC1200 & HG403700 & & & \\
\hline Streptomyces sp. & BCC1203 & HG423699 & & & \\
\hline Streptomyces sp. & BCC1204 & HG423698 & & & \\
\hline
\end{tabular}

TType strains

*NRRL, Northern Regional Research Laboratory culture collection, maintained by the USDA Agricultural Research Service, Peoria, Illinois, USA; CBS, Centraalbureau Voor Schimmelcultures, Utrecht, the Netherlands; BCC, Bacterial Culture Collection, Forestry and Agriculture Biotechnology Institute, University of Pretoria, Pretoria, South Africa. References to the publications in which three unnamed isolates (SA3ActG, SPB078, SPB074) from private collections were studied, are provided at the isolate numbers. 


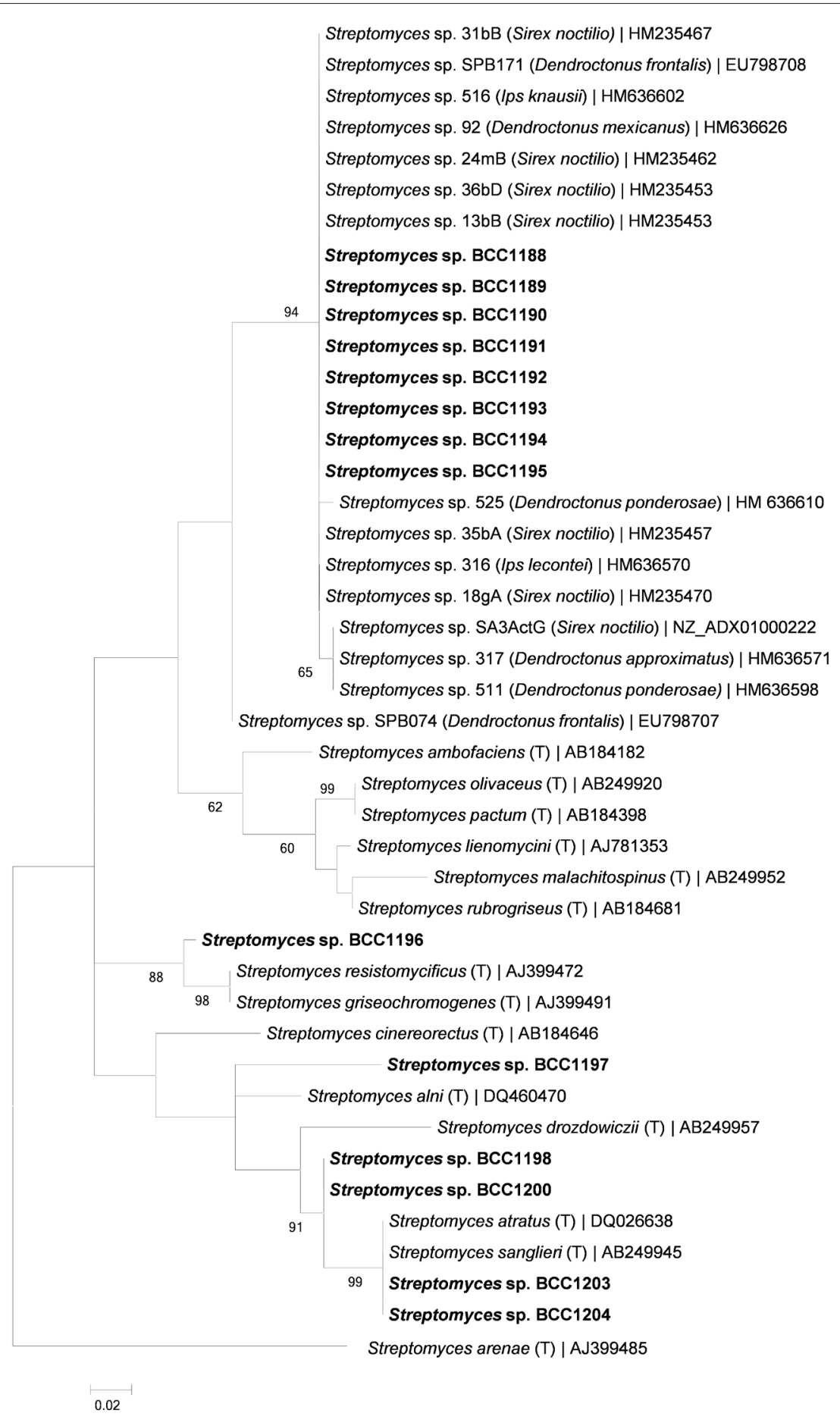

Figure 1: Maximum likelihood tree representing the 16S rRNA gene of all isolates from this study (in bold type) with closest matching type strains and isolates from other pine-infesting insects. Type strains are indicated by $(T)$ and host names are included for sequences from Streptomyces spp. from pine-infesting insects. Streptomyces arenae was used as the outgroup.

Although separate from the type strains of $S$. griseochromogenes and S. resistomycificus, BCC1196 formed a well-supported (88\%) cluster with these type strain sequences (Figure 1).

\section{Multi-locus sequence analysis}

All Streptomyces spp. isolates from pine-infesting insects, including eight isolates from this study, formed a clade with $100 \%$ bootstrap support in the multi-gene phylogeny (Figure 2). This clade was split between a branch consisting of a single isolate from $D$. frontalis (Streptomyces spp. SPB074) ${ }^{13,28}$ and another clade that contained two branches, one with the eight isolates from this study and the other a clade with isolates from Sirex noctilio (Streptomyces sp. SA3ActG) ${ }^{29}$ and $D$. frontalis (Streptomyces spp. SPB074) ${ }^{28}$. All of these branches were well supported. The type strain sequence matching most closely to the larger clade, including all isolates from pine-infesting insects, was S. albidoflavus. 


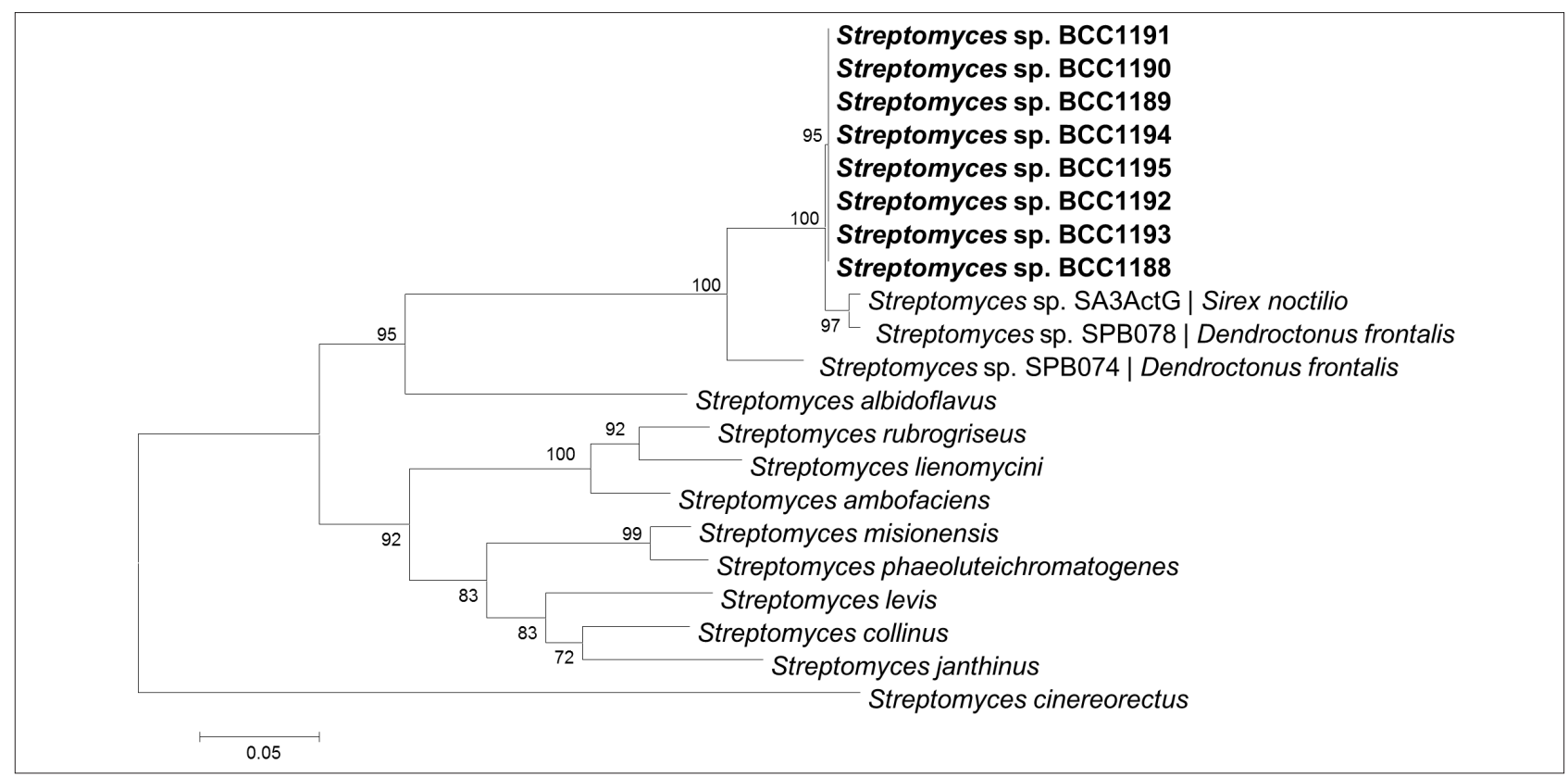

Figure 2: Maximum likelihood tree representing concatenated nucleotide sequence alignments of the gyrB, $r p o B$ and $\operatorname{trp} B$ genes of nine Streptomyces type strains, eight isolates from this study (bold type) and three Streptomyces strains isolated from other pine-infesting insects, as retrieved from the literature. ${ }^{10,25,26}$ Streptomyces cinereorectus was used as the outgroup.

\section{Dual-plate bioassay challenges}

In preliminary antifungal assays, 11 of the 15 cultures were found to have moderate to strong inhibitory effects on the Trichoderma sp. These 11 isolates were used in the subsequent in-vitro antifungal assays (Table 1). All of these actinomycete strains inhibited the three fungal species $D$. sapinea, Trichoderma sp. and 0 . ips, but to varying degrees. Of the three fungi, 0 . ips was the most strongly inhibited (Table 1).

The phylogenetically related isolates had similar levels of activity against the test fungi (Table 1). The isolates most similar to $S$. ambofaciens (BCC1988, BCC1989, BCC1990, BCC1991, BCC1992, BCC1993, BCC1994, BCC1995) all displayed moderate to strong $(6-10 \mathrm{~mm})$ levels of inhibition against both the Trichoderma sp. and $D$. sapinea.
These isolates had even higher levels of inhibition when tested against 0 . ips. Most other isolates with antifungal activity had moderate to strong inhibitory activity against Trichoderma sp. and $D$. sapinea, with a higher or very strong activity against 0 . ips. Isolate BCC1197 had very strong inhibitory activity against all test fungi.

When isolate BCC1188, representing the group of most common actinomycete isolates, and 0 . ips were simultaneously inoculated on fresh growth medium, in contrast to the previous assay in which 0 . ips was inhibited, fungal growth occurred until they came into close contact (Figure 3). Furthermore, living fungal material could still be isolated from the edges of the 0 . ips culture despite inhibition, showing that the fungus had not been killed by the actinomycete.

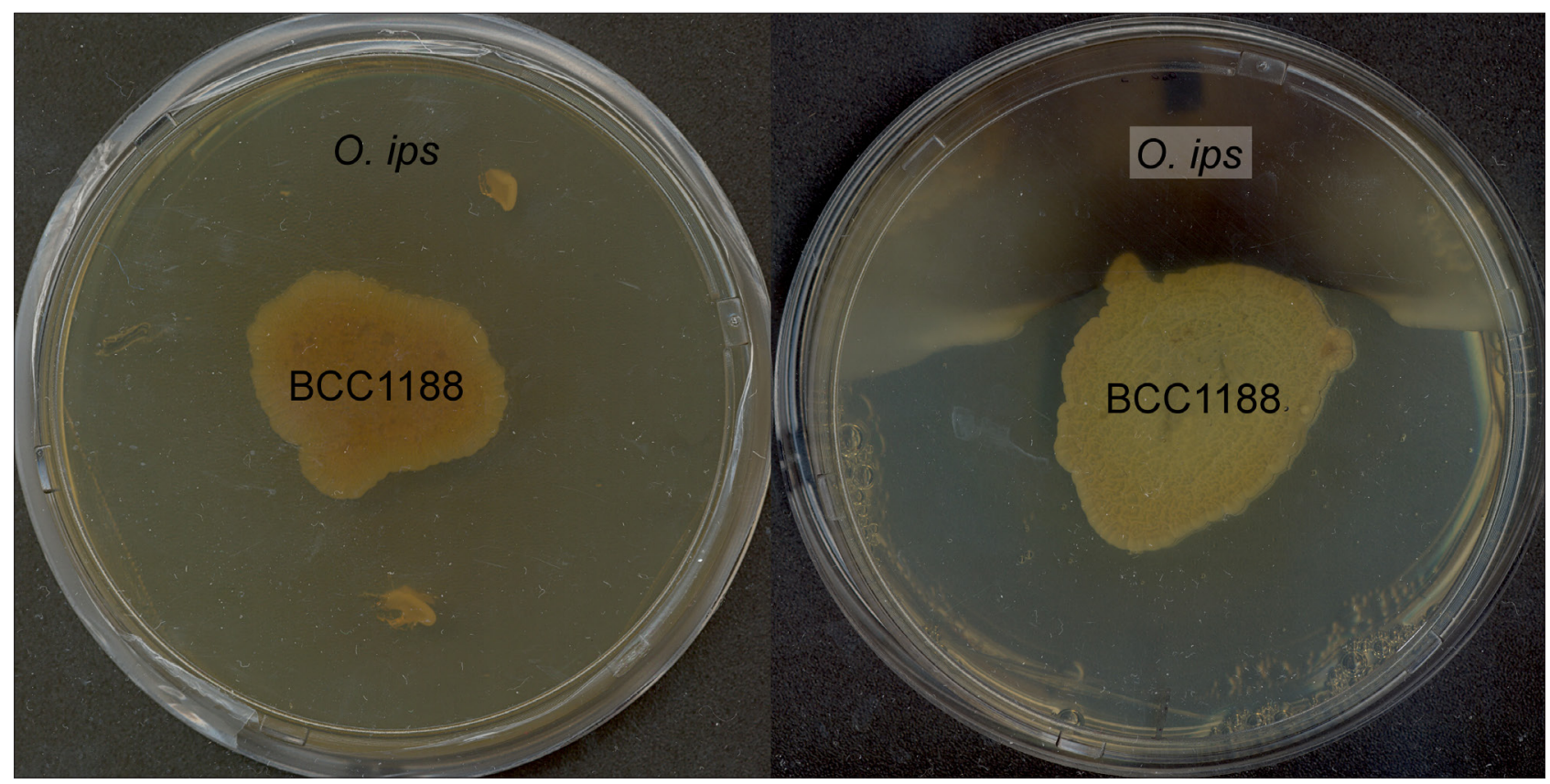

Figure 3: Bioassay challenge with isolate BBC1188 and Ophiostoma ips simultaneously inoculated (right) and bacteria inoculated 2 weeks before fungi (left) on yeast malt extract agar. This figure illustrates how a fungal isolate can grow uninhibited with a bacterial culture when inoculated at the same time. 


\section{Discussion}

In this study, 15 actinomycete isolates were collected from adult 0 . erosus beetles that infest Pinus spp. in South Africa. These bacteria were identified as actinomycetes based on colony morphology and comparisons of the 16S rRNA sequence data. The majority of these isolates represented Streptomyces spp. Although relatively few isolates of actinomycetes were recovered during this preliminary study, these bacteria appear to frequently encounter 0 . erosus. This is the first time that members of the actinomycetes have been reported from this or any other tree-infesting bark beetle in South Africa.

Based on the 16S rRNA phylogeny, one group of bacteria was consistently isolated from 0 . erosus. Comparison of the eight strains included in this group revealed that they grouped within one of the three clades of Streptomyces spp. that were identified by Hulcr et al. ${ }^{30}$ This clade also included a strain isolated from the pine-infesting beetle $D$. frontalis ${ }^{13,28}$ and cellulose degrading Streptomyces spp. associated with a pineinfesting siricid wasp, Sirex noctilio ${ }^{30,31}$. Further analysis based on several housekeeping genes showed that isolates from $S$. noctilio and $D$. frontalis from the USA were closely related with the isolates from 0 . erosus in South Africa. These isolates most likely represent the same species. This lineage is also associated with another isolate from $D$. frontalis, and they most likely share a common ancestor. The clade formed by our isolates and those from S. noctilio and $D$. frontalis was identified in another study. ${ }^{32}$ Several previously reported isolates from pine-infesting insects ${ }^{13,28,30,31}$ were grouped into two clades, based on their core genomes. One of these clades, containing a single isolate from both $S$. noctilio ${ }^{31}$ and $D$. ponderosae had remarkable lignocellulose digestion capacity. Another group, containing the exact isolates from $S$. noctilio ${ }^{31}$ and $D$. frontalis ${ }^{13}$ used in our phylogeny, had significantly less lignocellulose hydrolytic capabilities. The data suggest that this undescribed Streptomyces species has a strong association with insects associated with pine trees and that it could be a common inhabitant in this niche. According to Book et al. ${ }^{32}$, one of their clades of Streptomyces isolates is well adapted to thrive and utilise the abundant lignocellulosic substrates in the pine tree environment. The exact niche for members of the clade containing isolates from this study remains unclear, but our findings suggest that they are common and often encountered by pineinfesting insects, although a strong biological association with 0 . erosus is precluded by their low frequency.

The low frequency at which the actinomycetes were isolated in this study corresponded with the findings of Hulcr et al. ${ }^{30}$ who found that Streptomyces associates of North American bark beetles occur at low frequency. These low frequencies preclude definite conclusions regarding specific interactions between beetles and actinomycetes. The low frequency of isolation also suggests that this association is not essential for the beetles and fungi involved. However, our results suggest that it is most likely not a completely random association. Wider sampling, throughout the life cycle of the beetle and using more sensitive techniques (e.g. next-generation sequencing), will be required to conclude on the true frequency of interaction between these organisms. One possible scenario is that Streptomyces spores are more numerous on beetles when emerging from galleries and less abundant on beetles at the end of their life cycle - which is when they were sampled in this study. Contaminating bacteria from galleries could also preclude successful isolation of slower-growing actinomycetes.

The bioassays to test the potential effect of the Streptomyces spp. on fungi in 0 . erosus galleries showed that several of these bacteria have antifungal properties. The selection of test fungi used for the assay included a common saprophyte (Trichoderma sp.), an endophyte and opportunistic pathogen of Pinus spp. (D. sapinea), and the fungal symbiont of 0 . erosus. The levels of inhibition varied amongst test strains, ranging from weak to very strong. The most frequently isolated strains were able to inhibit all test fungi, including 0 . ips, the most common fungal symbiont to 0 . erosus. Previous studies on insect-fungus associated actinomycetes have suggested that beneficial fungi should be inhibited to a lesser extent than parasitic or other saprobic fungi. ${ }^{11-13}$ The beneficial fungal associate of the southern pine beetle is weakly inhibited compared with the parasitic 0 . minus..$^{13}$ This is also commonly believed to be the case in fungus-growing ants, in which the observed inhibition against Escovopsis spp. is higher than that against the mutualistic basidiomycetes ${ }^{11,12}$, although some have suggested that the beneficial cultivar is also harmed ${ }^{33}$. This result suggests that Streptomyces isolates collected in this study are unlikely to be associates of 0 . erosus, but may be linked to this beetle through another common partner, such as pine trees or mites.

Although it did not appear that the isolated Streptomyces spp. directly benefitted 0 . ips, it remains possible that they play some role in the ecology of these fungi and the associated beetles. For example, the fungal symbionts of the beetles such as 0 . ips are inoculated into the newly formed galleries at the time of infestation, either directly from the beetle's exoskeleton or with the help of mites. ${ }^{34,35}$ These fungi become established and dominate the niche, and it is likely that contaminating saprophytes enter the niche only at a later stage. If the antibiotic-producing Actinobacteria are introduced at the same time as the fungal associates, there would be sufficient opportunity for the fungus to establish itself and penetrate the wood before widespread colonisation of the bacteria. However, once the bacteria are established and producing antibiotics in the galleries, these would then be protected against possible harmful saprophytes that are expected to enter later. Simultaneous inoculation of Streptomyces spp. and the fungal symbiont on medium showed that 0 . ips can initially colonise large amounts of the resource and grow to the edge of the bacterial colony, before inhibition is seen. The results might suggest that 0 . ips can survive, while other saprophytes subsequently introduced may be inhibited completely. However, as it is not explicitly known that 0 . ips is beneficial to its bark beetle symbionts, the possibility exists that it is a mite associate that has no beneficial effects for the beetle, or that it might even be detrimental to beetle fitness and development. Therefore, partial inhibition of 0 . ips does not necessarily equate to having an impact on the survival of 0 . erosus.

This study represents the first investigation of actinomycetes associated with insects in South Africa and we have shown that Streptomyces spp. are occasional symbionts of 0 . erosus in this country. Several of the isolates formed part of a group of symbionts associated with bark beetles and a pine-infesting woodwasp in North America. ${ }^{13,30}$ This finding suggests some link between this Streptomyces species and the Pinus environment, which deserves further investigation. This species could have entered South Africa with Pinus planting stock or, given that they are apparently common to other pine-infesting bark beetles, it is likely that they entered South Africa with these insects. Future work should investigate the presence of similar Streptomyces spp. on other insects associated with Pinus spp. across different geographical ranges. The specific role in the galleries of 0 . erosus and the biology of this bark beetle should also be surveyed using culture-independent methods.

\section{Authors' contributions}

S.N.V., M.J.W., Z.W.d.B. and B.S. conceptualised the research. Z.R.H., S.N.V. and Z.W.d.B. conducted the experiments and analysed the data. All authors contributed to the interpretation of the results, and the writing and editing of the manuscript.

\section{References}

1. Tribe GD. Phenology of Pinus radiata log colonization and reproduction by the European bark beetle Orthotomicus erosus (Wollaston) (Coleoptera: Scolytidae) in the south-western Cape province. J Entomol Soc S Afr. 1990;53:117-126.

2. Hurley BP, Hatting HJ, Wingfield MJ, Klepzig KD, Slippers B. The influence of Amylostereum areolatum diversity and competitive interactions on the fitness of Sirex parasitic nematode Deladenus siricidicola. Biol Control. 2012;61:207-214. http://dx.doi.org/10.1016/j.biocontrol.2012.02.006

3. Zhou XD, De Beer ZW, Wingfield BD, Wingfield MJ. Ophiostomatoid fungi associated with three pine-infesting bark beetles in South Africa. Sydowia. 2001;53(2):290-300.

4. Romón $P$, Zhou X, Iturrondobeitia JC, Wingfield MJ, Goldarazena A. Ophiostoma species (Ascomycetes: Ophiostomatales) associated with bark beetles (Coleoptera: Scolytinae) colonizing Pinus radiata in northern Spain. Can J Microbiol. 2007;53(6):756-767. http://dx.doi.org/10.1139/W07-001 
5. Zhou XD, De Beer ZW, Wingfield BD, Wingfield MJ. Infection sequence and pathogenicity of Ophiostoma ips, Leptographium serpens and L. Iundbergii to pines in South Africa. Fungal Divers. 2002;10:229-240.

6. Six DL, Wingfield MJ. The role of phytopathogenicity in bark beetle-fungus symbioses: A challenge to the classic paradigm. Annu Rev Entomol. 2011;56(1):255-272. http://dx.doi.org/10.1146/annurev-ento-120709-144839

7. Lechevalier HA, Lechevalier MP. Biology of actinomycetes. Annu Rev Microbiol. 1967;21:71-100. http://dx.doi.org/10.1146/annurev. mi.21.100167.000443

8. Watve MG, Tickoo R, Jog MM, Bhole BD. How many antibiotics are produced by the genus Streptomyces? Arch Microbiol. 2001;176:386-390. http:// dx.doi.org/10.1007/s002030100345

9. Ruddick SM, Williams ST. Studies on the ecology of actinomycetes in soil. V. Some factors influencing the dispersal and adsorbtion of spores in soil. Soil Biol Biochem. 1972;4:93-100. http://dx.doi.org/10.1016/00380717(72)90046-6

10. Kaltenpoth M. Actinobacteria as mutualists: General healthcare for insects? Trends Microbiol. 2009;17:529-535. http://dx.doi.org/10.1016/j. tim.2009.09.006

11. Currie CR, Scott JA, Summerbell RC, Malloch D. Fungus-growing ants use antibiotic producing bacteria to control garden parasites. Nature. 1999;398:701-704. http://dx.doi.org/10.1038/19519

12. Cafaro MJ, Currie CR. Phylogenetic analysis of mutualistic filamentous bacteria associated with fungus-growing ants. Can J Microbiol. 2005;51:441446. http://dx.doi.org/10.1139/w05-023

13. Scott JJ, Oh DC, Yuceer MC, Klepzig KD, Clardy J, Currie CR. Bacterial protection of a beetle-fungus mutualism. Science. 2008;322:63. http://dx.doi. org/10.1126/science. 1160423

14. Whiffen AJ. The activity in vitro of cycloheximide (actidione) against fungi pathogenic to plants. Mycologia. 1950;42:253-258. http://dx.doi. org/10.2307/3755437

15. Harrington TC. Ecology and evolution of mycophagous bark beetles and their fungal partners. In: Vega FE, Blackwell M, editors. Ecological and evolutionary advances in insect-fungal associations. New York: Oxford University Press; 2005. p. 257-291.

16. Hsu SC, Lockwood JL. Powdered chitin agar as a selective medium for enumeration of actinomycetes. Appl Microbiol. 1975;29:422.

17. Edwards U, Rogall T, Blöcker H, Ernde M, Böttger E. Isolation and direct complete nucleotide sequence determination of entire genes. Characterization of a gene coding for 16S ribosomal RNA. Nucleic Acids Res. 1989;17:78437853. http://dx.doi.org/10.1093/nar/17.19.7843

18. Guo Y, Zheng W, Rong X, Huang Y. A multilocus phylogeny of the Streptomyces griseus 16S rRNA gene clade: use of multilocus sequence analysis for streptomycete systematics. Int J Syst Evol Microbiol. 2008;58:149-159. http://dx.doi.org/10.1099/ijs.0.65224-0

19. Rong X, Guo Y, Huang Y. Proposal to reclassify the Streptomyces albidoflavus clade on the basis of multilocus sequence analysis and DNA-DNA hybridization, and taxonomic elucidation of Streptomyces griseus subsp. solvifaciens. Syst Appl Microbiol. 2009;35:7-18. http://dx.doi.org/10.1016/j. syapm.2009.05.003

20. Altschul SF, Gish W, Miller W, Myers EW, Lipman DJ. Basic local alignment search tool. J Mol Biol. 1990;215:403-410. http://dx.doi.org/10.1016/ S0022-2836(05)80360-2
21. Benson DA, Karsch-Mizrachi I, Lipman DJ, Ostell J, Wheeler DL. GenBank. Nucleic Acids Res. 2005;33:D34-D38. http://dx.doi.org/10.1093/nar/gki063

22. Maidak BL, Cole JR, Lilburn TG, Parker CTJ, Saxman PR, Farris RJ, et al. The RDP-II (Ribosomal Database Project). Nucleic Acids Res. 2001;29:179-206. http://dx.doi.org/10.1093/nar/22.17.3485

23. Katoh K, Kuma K, Toh H, Miyata T. MAFFT version 5: Improvement in accuracy of multiple sequence alignments. Nucleic Acids Res. 2005;33:511-518. http://dx.doi.org/10.1093/nar/gki198

24. Vaidya G, Lohman DJ, Meier R. SequenceMatrix: Concatenation software for the fast assembly of multi-gene datasets with character sets and codon information. Cladistics. 2010;27:121-123. http://dx.doi.org/10.1111/j.10960031.2010.00329.x

25. Guindon S, Gascuel 0 . A simple, fast and accurate method to estimate large phylogenies by maximum-likelihood. Syst Biol. 2003;52:696-704. http:// dx.doi.org/10.1080/10635150390235520

26. Darriba D, Taboada GL, Doallo R, Posada D. jModeltest 2: More models, new heuristics and parallel computing. Nat Methods. 2012;9:772. http://dx.doi. org/10.1038/nmeth.2109

27. Tamura K, Peterson D, Peterson N, Stecher G, Nei M, Kumar S. MEGA 5: Molecular evolutionary genetics analysis using maximum likelihood, evolutionary distance, and maximum parsimony methods. Mol Biol Evol. 2011;28:2731. http://dx.doi.org/10.1093/molbev/msr121

28. BlodgettJAV, OhD-C, CaoS, Currie CR, KolterR, Clardy J. Common biosynthetic origins for polycyclic tetramate macrolactams from phylogenetically diverse bacteria. Proc Natl Acad Sci USA. 2010;107(26):11692-11697. http:// dx.doi.org/10.1073/pnas.1001513107

29. Takasuka TE, Book AJ, Lewin GR, Currie CR, Fox BG. Aerobic deconstruction of cellulosic biomass by an insect-associated Streptomyces. Sci Reports. 2013;3, Art. \#1030, 10 pages. http://dx.doi.org/10.1038/srep01030

30. Hulcr J, Adams AS, Raffa KF, Hofstetter RW, Klepzig KD, Currie CR. Presence and diversity of Streptomyces in Dendroctonous and sympatric bark beetle galleries across North America. Microbial Ecol. 2011;61:759-768. http:// dx.doi.org/10.1007/s00248-010-9797-0

31. Adams AS, Jordan MS, Adams SM, Suen G, Goodwin LA, Davenport KW, et al. Cellulose degrading bacteria associated with the invasive woodwasp Sirex noctilio. ISME J. 2011;5:1323-1331. http://dx.doi.org/10.1038/ ismej.2011.14

32. Book AJ, Lewin GR, McDonald BR, Takasuka TE, Doering DT, Adams AS, et al. Cellulolytic Streptomyces strains associated with herbivorous insects share a phylogenetically linked capacity to degrade lignocellulose. Appl Environ Microbiol. 2014;80(15):4692-4701. http://dx.doi.org/10.1128/AEM.0113314

33. Sen R, Ishak HD, Estrada D, Dowd SE, Hong E, Mueller UG. Generalized antifungal activity and 454-screening of Pseudonocardia and Amycolatopsis bacteria in nests of fungus-growing ants. Proc Natl Acad Sci USA. 2009;106(42):17805-17810. http://dx.doi.org/10.1073/pnas.0904827106

34. Moser JC, Perry TJ, Solheim H. Ascospores hyperphoretic on mites associated with Ips typographus. Mycol Res. 1989;93:513-517. http:// dx.doi.org/10.1016/S0953-7562(89)80045-0

35. Klepzig KD, Moser JC, Lombardero MJ, Ayres MP, Hofstetter RW, Walkinshaw CJ. Mutualism and antagonism: Ecological interactions among bark beetles, mites and fungi. In: Jeger MJ, Spence NJ, editors. Biotic interactions in plantpathogen associations. Wallingford: CAB International; 2001. p. 237-268. http://dx.doi.org/10.1079/9780851995120.0000 